\title{
Montículos del sector Sur de la cuenca de la Laguna Merín, oven mounds australianos y analogía
}

\author{
Mounds of the South sector of the Merin Lagoon basin, australian oven mounds and analogy
}

\author{
Roberto Bracco Boksar* \\ Christopher Duarte* \\ Daniel Loponte***
}

\author{
Palabras claves: \\ Montículos \\ Procesos de formación \\ Hornos de pozo \\ Analogía etnográfica
}

Keywords:

Mounds

Cultural formation

Pit ovens

Ethnographic analogy

\begin{abstract}
Resumen: No se conocen fuentes históricas que describan la funcionalidad o los procesos que llevaron a la generación de los montículos del sur de la cuenca de la laguna Merín (CLM), este-nordeste del Uruguay. Por ello, su interpretación se ha basado a menudo en algunas de sus características arqueológicas. En otras regiones del mundo, como en el norte de Australia, montículos artificiales similares han sido registrados etnográficamente, señalando los comportamientos respecto de su proceso de elevación, proveyendo un modelo conductual que puede ser explorado en términos analógicos para su aplicación a nuestro caso de estudio. En este trabajo, precisamente, desarrollamos la validez de la inferencia analítica basada en la analogía relacional que permite comparar las propiedades de ambos tipos de estructuras, evaluando las evidencias contrastadoras para los montículos de la CLM, junto con la información arqueológica disponible para tal efecto. Para ello, presentamos diferentes fuentes etnohistóricas de la región de Victoria, que describen los procesos de formación de los oven mounds australianos y algunas de sus características estructurales, para desarrollar el proceso analógico y de generación de hipótesis contrastadoras, evaluando finalmente las propiedades arqueológicas de los montículos de la CLM.
\end{abstract}

Abstract: There are no known historical sources that describe the functionality or the processes that led to the generation of the southern mounds of the Merín lagoon basin (CLM) located in the east-northeast of Uruguay. Therefore, the interpretation of these structures has often been based on some of their archaeological features. In other regions of the world, such as northern Australia, similar artificial mounds have been ethnographically recorded, indicating the behaviors linked to their elevation process, providing a behavioral model that can be explored in analogical terms for application to our case study. In this work, precisely, we develop the validity of the analytical inference based on the relational analogy that allows us to compare the properties of both types of structures, evaluating the contrasting evidence for the mounds of the CLM, together with the archaeological information available for this purpose. To do this, we present different ethnohistorical sources from the Victoria region, which describe the formation processes of Australian oven mounds and some of their structural characteristics, to develop the analogical process and the generation of contrasting hypotheses, finally evaluating the archaeological properties of the mounds of the CLM.

Recebido em 30 de novembro de 2020. Aprovado em 19 de abril de 2021.

\footnotetext{
* Facultad de Humanidades y Ciencias de la Educación, Universidad de la República / Ministerio de Educación y Cultura. Laboratorio Luminiscencia Facultad de Ciencias, Iguá 4225, 11400 Montevideo, Uruguay. E-mail: braccoboksar@montevideo.com.

** UNCIEP, Instituto de Ecología y Ciencias Ambientales, Facultad de Ciencias, Universidad de la República, Uruguay, Iguá 4225,11400 Montevideo, Uruguay. E-mail: christopherduarte1@gmail.com.

*** Consejo Nacional de Investigaciones Científicas y Técnicas - Instituto Nacional de Antropología y Pensamiento Latinoamericano. 3 de Febrero 1378 (C1426BJN), Ciudad de Buenos Aires. E-mail: dashtown@gmail.com.
} 


\section{Introducción: etnohistoria y montículos}

El territorio del actual Uruguay fue ocupado tardíamente por los europeos. Durante los primeros siglos de la conquista era "tierra sin ningún provecho" por no ofrecer ni oro ni plata, a lo que se sumó el carácter belicoso atribuido a sus indígenas (VERDESIO, 1996). En el siglo XVII su condición cambia por la introducción y rápida multiplicación del ganado (BARRIOS PINTOS, 2011). Es muy probable que entre el siglo XVII y XVIII el contacto de los grupos originarios con el mundo europeo se diera más frecuentemente a través de vacas y caballos que vis a vis con los colonizadores. Estas circunstancias ocasionaron dos consecuencias. La primera es que las referencias etnográficas para el período histórico temprano (anteriores al siglo XVII) son muy escasas, escuetas y geográficamente limitadas, reseñando en forma poco detallada a aquellos grupos que frecuentaban las márgenes de los ríos por los que transitaban los europeos (BRACCO, 1998). La segunda consecuencia es que cuando las fuentes etnohistóricas comienzan a ser más abundantes, ya se refieren a grupos transformados en sociedades ecuestres (BRACCO, 2004). A todo ello se suma el exterminio en el año 1830 de casi la totalidad de los indígenas que aún no habían sido totalmente absorbidos por la sociedad colonial o nacional (BRACCO, 2017). Estos procesos históricos incidieron de alguna manera en los diseños de investigación arqueológica y en las interpretaciones derivadas, las cuales carecen de analogías históricas directas válidas, o son sumamente acotadas.

Los montículos arqueológicos de las llanuras de Uruguay y del sur de Brasil son elevaciones artificiales de tierra que integran desechos de actividad humana (restos óseos, artefactos líticos y tiestos, así como inhumaciones). Se ubican en la bioma Pampa, desde el sur de la cuenca de la laguna de los Patos hasta la cuenca de la laguna de Castillos, en planicies inundables o en lomadas y serranías que se proyectan hacia bañados. También los hallamos en la cuenca media y superior del río Negro (Figura 1) (BRACCO et al., 2020; COPÉ, 1991; MILHEIRA; GIANOTTI, 2018). Los montículos a los que nos referimos en este trabajo corresponden a los que se encuentran en el sur de la CLM, donde exhiben plantas circulares a elípticas con diámetros en el orden de los $35 \mathrm{~m}$ y alturas que alcanzan los 7 $\mathrm{m}$ (Figura 2). Sus cronologías absolutas cubren el período 5500 - 200 AP (BRACCO et al., 2015: Tabla 1). El hallazgo de material europeo en su interior corroboraría que alcanzaron el período histórico (CABRERA; MAROZZI, 2001; PINTOS BLANCO; CAPDEPONT, 2001). Sin embargo, hasta hoy no se cuenta con ninguna fuente documental que los mencione. Sus fechados más antiguos $\left(5420 \pm 260\right.$ y $5400 \pm 140$ años ${ }^{14} \mathrm{C}$ aP) proceden de la región de India Muerta - Paso Barranca (BRACCO et al., 2015: Tabla 1); se ha indicado que su surgimiento sería coetáneo con un período de transición a condiciones climáticas más frías y secas (BRACCO et al., 2005, 2011; DEL PUERTO, 2015; DEL PUERTO et al., 2013; IRIARTE, 2003).

El registro arqueológico señala que los grupos que los erigieron y ocuparon eran cazadores-recolectores-pescadores, los que habrían integrado una horticultura a pequeña escala (BRACCO et al., 2020b; DEL PUERTO, 2015; GIANOTTI et al., 2013; MUT, 2015). Los cérvidos (Blastocerus dichotomus, Ozotoceros bezoarticus y Mazama sp.), nutria (Myocastor coypus) y peces dominan el registro arqueofaunístico (MORENO, 2014). Restos macro botánicos testimonian la recolección de frutos de palmeras, Butia odorata y Syagrus romanzoffiana (SUÁREZ, 2018). Restos microbotánicos, principalmente silicofitolitos, han sido señalados como evidencias tempranas del cultivo de calabaza, porotos y maíz ( 2500 aP) junto al manejo de algunas especies silvestres (DEL PUERTO, 2015; GIANOTTI et al., 2013; IRIARTE et al., 2004). El registro isotópico $\left({ }^{13} \mathrm{C}\right.$ y ${ }^{15} \mathrm{~N}$ del colágeno; $\delta^{13} \mathrm{C}$ de la bioapatita, la diferencia en los valores de $\delta^{13} \mathrm{C}$ entre la fracción colágeno y apatita ( $\Delta^{13}$ Ccolágeno-apatita) (DEL PUERTO, 2015; MUT, 2015) y la relación Sr/Ca de los restos óseos humanos recuperados en el sector sur de la cuenca, corresponden a una dieta basada en la caza-pesca-recolección, desarrollada en ambientes continentales, con un componente vegetal $\mathrm{C}_{3}$ importante, y donde la señal de maíz no se observa o es muy débil (BRACCO et al., 2000; DEL PUERTO, 2015; MUT, 2015). 
Se ha propuesto que los montículos fueron plataformas para ocupar áreas inundables, sitios mortuorios, de descarte, sitios rituales monumentales, demarcadores territoriales y/o de espacios públicos ("plazas"), o como un reflejo de sistemas multifuncionales que incluso habrían integrado sistemas hortícolas (BAEZA; PANARIO, 1999; BRACCO et al., 2000; GIANOTTI, 2015; IRIARTE et al., 2004; LÓPEZ, 2001; LOUREIRO, 2008; MILHEIRA; GIANOTTI, 2018; SCHMITZ, 1976). Actualmente coexisten dos líneas básicas de interpretación sobre ellos. Una los percibe como productos arquitectónicos o ingenieriles ("monumentos"; MILHEIRA; GIANOTTI, 2018, entre otros), cuyas débiles evidencias contrastadoras ya hemos discutido en otro lugar (BRACCO, 2006; DUARTE; BRACCO, 2021). La segunda línea de interpretación considera que son la consecuencia no intencional de un comportamiento recursivo secular, basado en las edades radiocarbónicas y en la estructura del registro arqueológico (BRACCO; URES, 1991; BRACCO, 2006; DUARTE; BRACCO, 2021). Teniendo en cuenta los datos cronológicos disponibles del proceso de formación de los mismos, consideramos factibles mecanismos equivalentes a los observados en los oven mounds australianos, proponiendo que el comportamiento recursivo y secular elevó los montículos de la región de India Muerta-Paso Barranca (Figura 1) a través de la generación de hornos de pozo (HP) y de sus residuos estructurales y de detritos asociados. Diferentes líneas de evidencia sustentan esta hipótesis. Las principales son: propiedades geoquímicas de la matriz, presencia y proporción de nódulos de tierra quemada (hasta el 30\% de la matriz) y edades OSL-TL iguales o similares (consistentes con edades ${ }^{14} \mathrm{C}$ ) para mismos niveles producidas a partir de diferentes fracciones de la matriz, lo cual indica que toda o casi toda la matriz fue calentada a temperaturas mínimas de 350C (BRACCO et al., 2019a, 2019b, 2020a, 2020b; DUARTE et al., 2017). En este trabajo, precisamos la estrategia analógica en relación a ambos tipos de estructuras (montículos CLM y oven mounds) para profundizar el potencial heurístico de la comparación (WYLIE, 1985).

\section{La analogía arqueológica}

Una de las funciones más comunes de la analogía en los estudios arqueológicos es que modelan implícitamente el registro físico, y por ello, de alguna manera, intenta explicarlo. Es frecuente que en este proceso se desarrollen hipótesis formales o subyacentes, como así también expectativas contrastadoras. El empleo de la analogía permite además estructurar con nuevas perspectivas el fenómeno a ser analizado, constituyendo una poderosa herramienta analítica que interactúa en diferentes órdenes durante el proceso de investigación. Dentro de este marco general, existe una gran pluralidad de aproximaciones dentro del uso de la analogía en las ciencias en general, que para los fines de nuestro estudio, las dividiremos en tres grandes categorías. La primera incluye a las analogías informales o débiles, donde no se logran conectar con algún grado de certidumbre las similitudes observadas, o estas presentan ciertas semejanzas que se establecen de manera exploratoria. Una segunda categoría pertenece a las analogías fuertes donde se establecen relaciones explicativas entre una gran parte de los términos de la comparación, si bien pueden existir o existen otros elementos que no pueden explicarse entre el fenómeno-fuente de la analogía, y el proceso o término de la comparación. Esta estructura analógica es menos estricta respecto a la isometría de los términos y de los procesos analizados, dado que algunos componentes pueden ser similares y otros diferentes; es decir, no todas propiedades pueden ser explicadas por una sola fuente analógica, o no todos los componentes de los términos o procesos de la comparación son análogos. Finalmente, están las analogías completas, donde se verifica que todas las entidades y relaciones de la fuente analógica cumplen con los términos observados en el sujeto involucrado en la comparación, lo cual raramente se logra (GODOY, 2002; TOULMIN, 1958; TRILLAS, 1998).

El uso de la analogía en la arqueología incumbe las diferentes formas señaladas anteriormente, insertándose de manera muy variable en la práctica académica. No todos los trabajos de investigación que utilizan métodos analógicos los explicitan de manera formal, pero ciertamente el 
empleo de este recurso metodológico es cada vez más amplio, gracias al uso de numerosas tecnologías que hoy se aplican a la moderna investigación científica, incluidas las analogías experimentales (SEAWRIGTH, 2015). Estas últimas se basan en un modelo controlado de laboratorio o de campo ("métodos actualísticos"), o menos frecuentemente, mediante la analogía etnográfica, que es una variante de la anterior, donde algunos de los términos están bajo control (sea por observación directa, o por relato de terceros). Tanto la analogía que se basa en la observación directa, como aquella que utiliza fuentes etnográficas, tienen el mismo estatus epistemológico, ya que se basan en un argumento inductivo como todo proceso analógico, que incorpora las semejanzas y diferencias entre las partes sujetas a comparación (STUART MILL, 1843). La estructura lógica de cualquiera de estas variantes tiene el mismo formato que adquiere la siguiente secuencia lógica: si P (fuente) y Q (sujeto) son similares respecto a las propiedades $\mathrm{a}, \mathrm{b}$ y c, y se observa que $\mathrm{P}$ tiene la propiedad o término $\mathrm{x}$, se colige que es probable que $\mathrm{Q}$ la tenga (FERRATER MORA, 1979), generando concurrentemente expectativas de contrastación, y constituyendo un ejemplo más de la metodología inferencial de carácter probabilístico. Por ello, el fin último de todas las formas de aplicación del método analógico es generar modelos explicativos de diferente alcance.

Desde los inicios de la arqueología en el continente americano, se ha buscado interpretar el registro arqueológico según las culturas etnográficas locales, siempre y cuando existieran condiciones para ello, tales como la cronología de los contextos, las propiedades materiales observadas en los mismos, y la pertinencia/validez de la información etnográfica. Estas comparaciones en particular siguieron la conexión evolutiva entre el sujeto y la fuente, en consonancia con la teoría darwiniana, ya que las culturas etnográficas de cada región son consideradas descendientes con modificación de aquellas que dejaron el registro arqueológico más tardío (LYMAN; O'BRIEN, 2001). Esta aproximación adquiere la forma de una clásica analogía directa, en oposición a la analogía de carácter general o discontinua, distinción que fue tempranamente efectuada en la arqueología americana (WILLEY, 1953). La analogía general o discontinua considera que las mismas fuerzas que actúan en el presente actuaron en el pasado, asumiendo como verdaderos los principios del uniformismo y actualismo (GÁNDARA, 1990; VILA; ESTÉVEZ, 2000; LANE， 2014; CAMERON, 1993). De esta manera, trabajan bajo los conceptos del paralelismo o la convergencia evolutiva (HALL, 2003).

Más allá de las diferencias, tanto la analogía histórica como la general, fueron utilizadas de manera conjunta desde los inicios de los estudios arqueológicos en Sudamérica para explicar el registro arqueológico (AMEGHINO, 1880). No obstante, hubo una clara preminencia de la analogía directa. Esto se debió a la disponibilidad inmediata en amplias regiones, de datos etnográficos locales, y por el contrario, a la baja accesibilidad y a la escasa producción de literatura etnográfica mundial; situación que comenzó a cambiar recién a mediados del siglo pasado. No obstante, por más que admitamos que la analogía directa tiene, en ocasiones, una fuerte capacidad explicativa debido a la conexión histórico-evolutiva de las partes, debemos reconocer que su validez es cada vez más endeble a medida que fuente y sujeto se distancian en el tiempo. Inclusive, las sociedades pueden tener cambios radicales en lapsos muy cortos. Por lo tanto, carece de profundidad temporal, y solo puede aplicarse con un cierto criterio crítico y selectivo a los contextos arqueológicos más tardíos. Por otro lado, en regiones como Europa, la frecuente imposibilidad de tener análogos históricos directos llevó a los arqueólogos a plantear el uso de análogos generales, observando que las comparaciones debían de realizarse entre sociedades que tuvieron entornos ecológicos y sistemas organizacionales semejantes, buscando explicaciones basadas en el paralelismo o la convergencia (CLARK, 1953; ver también WYLIE, 1985). Con el advenimiento de la Nueva Arqueología, la dicotomía entre ambos tipos de analogías cambió de eje discursivo, desplazando el origen de las analogías a los procesos de contrastación que se podían elaborar a partir de ellas. De esa manera, sin importar cuál fuera su origen, las analogías comenzaron a ser consideradas basales para la construcción de hipótesis, pasando a ser un elemento central dentro de una estrategia de 
investigación hipotético-deductiva (BINFORD, 1968). A efectos de ampliar la base analógica, se dio inicio a la etapa de los estudios etnoarqueológicos, permitiendo ampliar el estrecho campo de información general sobre los comportamientos y los efectos materiales de las conductas del pasado (BINFORD, 1967, 1968, 1978, 1983). Sin embargo, las posturas historicistas decimonónicas que persistieron dentro de las llamadas corrientes post-procesualistas, sostuvieron la imposibilidad de utilizar analogías generales o discontinuas, ya que los registros arqueológicos están históricamente contextualizados (HODDER, 1988). No obstante, más allá del relativismo del planteo y del hecho de que obviamente las conductas tienen contextos histórico-evolutivos propios, está crítica apunta solamente al uso heurístico de la analogía general o discontinua, no a su uso como fuente de hipótesis, que es el aspecto central que le otorgó la Nueva Arqueología. Por otro lado, según señala Gándara (1990, p. 19) "las corrientes historicistas están utilizando la analogía de manera velada y en plena contradicción a lo que postulan como su ontología... cualquier marco teórico que piense que es imposible construir o encontrar generalidades, se niega a sí mismo la posibilidad de hacer analogías...”.

Para concluir este apartado, es oportuno señalar que el fortalecimiento en la generación de hipótesis de origen analógico, depende en gran medida de su diseño, del grado de similitud y de la cantidad de aspectos comparados entre la fuente y el objeto, como asimismo de la diversidad de fuentes y la proyección de las conclusiones en relación con las premisas iniciales (LANE, 2014; WYLIE, 1985).

\section{Oven mounds y montículos del sur de la CLM}

Los montículos son un rasgo arqueológico característico muy frecuente en la CLM, como así también en otras regiones de Sudamérica y de otras regiones del mundo. Por ejemplo, son relativamente comunes en diferentes partes de Amazonia (PRÜMERS, 2017) y Pantanal (SCHMITZ; ROGGE, 2015) y menos frecuentes en el humedal del Paraná inferior (CASTIÑEIRA et al., 2014,
LOPONTE et al., 2016), si bien en todas estas regiones persisten problemas metodológicos de diferenciación entre aquellos que fueron efectivamente elevados de una manera intencional de aquellos que son producto de la elevación por conductas domésticas a lo largo de los siglos (LÓPEZ MAZZ et al., 2016; PRÜMERS, 2017). Montículos semejantes a los de la CLM han sido identificados en las cuencas inferiores de los ríos West, South Alligator y Murray, en Australia (BROCKWELL, 2006; JONES, et al., 2017; WESTELL; WOOD, 2014). Dado que estas últimas estructuras se considerarán como fuente analógica en este estudio, las describiremos con mayor detalle. Estos montículos de tierra poseen plantas circulares $\mathrm{u}$ ovales, con ejes mayores de hasta 120 metros, alcanzando hasta 2 metros de altura. Frecuentemente se presentan agrupados en los límites de las planicies de inundación. Los más antiguos exhiben edades radiocarbónicas de 4600 años, para su base (BROCKWELL, 2006, Tabla 2). Se elevaron de manera progresiva en lapsos de entre 300 a 2500 años (JONES et al., 2017, Figura 2). Los que se hallan en las planicies fluviales se han interpretado como campamentos estacionales ocupados antes y después de las inundaciones, cuando los vegetales con bulbos, rizomas, tubérculos o raíces suculentas están disponibles para su consumo (JONES et al., 2017, p.51). Se ha propuesto, a partir de información etnohistórica y de la presencia en ellos de fragmentos de termóforos confeccionados con sedimentos, que su crecimiento es provocado principalmente por la acumulación de los desechos que produce la confección y el uso de HP, y de ahí su denominación de oven mounds (BROCKWELL, 2006; CAMPANELLI et al., 2018; JONES et al., 2017, p. 47-53; MARTIN, 2011; WESTELL; WOOD, 2014). Los HP de la cuenca del Murray-Darling se emplearon principalmente en la cocción de geófitos, donde Typha jugó un papel destacado. Mitchell (1839, en WESTELL; WOOD, 2014, p.45) describe altos montículos ("lofty mounds") que resultaron de su cocción cotidiana. Martin (2011) relaciona a los oven mounds con un proceso de intensificación iniciado al final del Holoceno medio, el cual se focalizó en los recursos de los humedales y que habría estado acompañado de un mayor grado de sedentarismo y 
territorialidad. Según Westell y Wood (2014, p. 8) los montículos se habrían convertido en marcadores importantes en el paisaje, identificando linajes ancestrales y respaldando la apropiación de sectores de concentración de recursos. Jones y colaboradores (2017, p. 53) destacan que pueden haber estado imbuidos de un significado cultural, social y/o espiritual, más allá de su función económica.

Los montículos del norte de Australia [...] son frecuentemente vistos por los aborígenes como anteriores a la ocupación humana del paisaje y por lo tanto tienen un significado cultural relacionado con la mitología del tiempo de los sueños y como sitios de inhumación [...]. Esto los convierte en marcadores importantes en el paisaje cultural contemporáneo (BROCKWELL, 2006, p. 54).

En el siguiente cuadro se presentan las principales propiedades que comparten los oven mounds australianos con los montículos del sur de la CLM.

Tabla 1: Cuadro comparativo de los oven mounds de Australia y los montículos de la región de India Muerta-Paso Barranca, sur de la CLM

\begin{tabular}{|c|c|c|}
\hline & Australian oven mounds* & Montículos sur CLM ${ }^{* *}$ \\
\hline Ubicación & $\begin{array}{l}\text { Planicies inundables y zonas aledañas. Próximos a } \\
\text { concentraciones de geófitos, entre otros Typha }\end{array}$ & $\begin{array}{l}\text { Planicies inundables y zonas aledañas. Próximos a } \\
\text { concentraciones de geófitos, entre otros Typha }\end{array}$ \\
\hline $\begin{array}{l}\text { Forma planta y } \\
\text { dimensiones }\end{array}$ & $\begin{array}{l}\text { Circular de } 30 \text { m diámetro, a alargada, alcanzando } \\
120 \mathrm{~m} \text { en su eje mayor. Altura hasta } 2 \text { metros. }\end{array}$ & $\begin{array}{c}\text { Circular a elíptica, con un diámetro promedio de } 35 \\
\text { m, alcanzando hasta } 100 \text { m y } 7 \text { metros altura. Altura } \\
\text { media } 2 \text { metros, aproximadamente (I. Muerta - P. } \\
\text { Barranca). }\end{array}$ \\
\hline $\begin{array}{l}\text { Hábito de } \\
\text { distribución }\end{array}$ & Dominantemente agrupados & Dominantemente agrupados \\
\hline $\begin{array}{l}\text { Economía atribuida } \\
\text { a sus constructores }\end{array}$ & $\begin{array}{l}\text { Cazadores-recolectores-pescadores focalizados en } \\
\text { recursos de áreas inundables. Explotación de } \\
\text { geófitos. } \\
\rightarrow \text { Intensificación luego cambio climático de } \\
\text { comienzos del Holoceno tardío }\end{array}$ & $\begin{array}{l}\text { Cazadores-recolectores-pescadores focalizados en } \\
\text { recursos de áreas inundables. Explotación de geófitos. } \\
\text { Horticultura de pequeña escala. } \\
\rightarrow \text { Intensificación luego cambio climático de } \\
\text { comienzos del Holoceno tardío. }\end{array}$ \\
\hline Matriz & Sedimento termoalterado & Sedimento termoalterado \\
\hline $\begin{array}{l}\text { Elementos que } \\
\text { integran la matriz }\end{array}$ & $\begin{array}{l}\text { Termóforos sedimentarios, en algunos casos hechos } \\
\text { a partir de fragmentos de nidos epigeos (termiteros) }\end{array}$ & $\begin{array}{l}\text { Termóforos sedimentarios, en algunos casos hechos a } \\
\text { partir de fragmentos de nidos epigeos (hormigueros) }\end{array}$ \\
\hline Restos & $\begin{array}{c}\text { Artefactos simples, confeccionados en rocas y } \\
\text { huesos, restos faunísticos, botánicos, carbón y } \\
\text { termóforos }\end{array}$ & $\begin{array}{c}\text { Artefactos simples confeccionados en piedra y hueso, } \\
\text { cerámica simple, restos faunísticos, botánicos, carbón } \\
\text { y termóforos }\end{array}$ \\
\hline Estructuras & Sepulturas, estructuras de combustión & Sepulturas, estructuras de combustión \\
\hline Edades máximas & $4600 \mathrm{a}{ }^{14} \mathrm{C}$ a.P. & $\begin{array}{c}5200 \mathrm{a}{ }^{14} \mathrm{C} \text { a.P. es la datación más antigua. Hacia el } \\
4800 \mathrm{a}{ }^{14} \mathrm{C} \text { a.P. se generaliza su presencia }\end{array}$ \\
\hline $\begin{array}{l}\text { Períodos de } \\
\text { crecimiento }\end{array}$ & Siglos - milenios & Siglos - milenios \\
\hline $\begin{array}{l}\text { Mecanismos de } \\
\text { crecimiento }\end{array}$ & Culturales (no intencionales) y naturales & Culturales (¿no intencionales?) y naturales \\
\hline
\end{tabular}

Fonte: Modificado de Bracco (2019). Base: Bracco (2006); Bracco et al. (2019; 2020a); Brockwell (2006); Jones et al. (2017);

López et al. (2017); Milheira y Gianotti (2018). 


\section{Aumentando la base inferencial}

En este apartado presentamos las tres fuentes etnohistóricas del siglo XIX, aportadas por colonizadores europeos de Australia. Las tres nos dejaron descripciones de HP realizados por los indígenas de la región de Victoria y de su relación con los oven mounds. Entre sí son altamente consistentes. La primera, escrita por Peter Beveridge (1869), es la más extensa y detallada. Según declaraciones de su autor, refiere a una realidad que observó a lo largo de 28 años. Luego que fundamenta la denominación de oven mounds para los montículos, resaltando que son "lugares para cocinar”, pasa a describir cuál es la práctica culinaria que les dio origen.

[...] una familia, o (según sea el caso) varias familias, que se han instalado en sus campamentos donde las posibilidades de comida son abundantes, tienen algo que cocinar, por ejemplo, diré un emú; cavan un hoyo de unos tres pies de diámetro y unos veinte o veinticinco centímetros de profundidad; este trabajo es siempre realizado por "Lubras"1 y sus únicos implementos son palos cavadores ("yam-sticks."). Si no hay piedras en los alrededores, se apartan cuidadosamente los trozos de tierra más tenaces encontrados durante la excavación. Cuando el agujero ha alcanzado la profundidad deseada se llena con leña sobre la cual se colocan los terrones seleccionados, luego se enciende la leña; cuando toda se consume ya los nódulos de tierra se han cocido hasta obtener la consistencia de ladrillo y, por supuesto, están al rojo vivo. Logrado este resultado, los terrones calientes se retiran con un par de tenazas aborígenes ("aboriginal tongs"), después de lo cual se barre cuidadosamente el hoyo y se coloca una capa de hierba húmeda sobre el fondo y los lados. El emú desmembrado se dispone cuidadosamente sobre la hierba y se cubre con más hierba húmeda; los terrones al rojo vivo se extienden por igual sobre la hierba, y luego se cubre todo con la tierra más fina que se había sacado del pozo. Si la cubierta de tierra es demasiado delgada para evitar que escape el vapor, se complementa con tierra excavada en las proximidades. Las cenizas nunca se usan como tapa del horno porque al ser finas, se colarían por los intersticios de la tierra al rojo vivo, y también la hierba, estropeando la comida. Antes de que el calor de los nódulos de tierra y del pozo mismo tenga tiempo de agotarse, la comida está tan perfectamente cocida como si se hubiera hecho en la mejor cocina. Terminada la cocción, se raspa la cubierta y estos restos (sedimento calcinado, cenizas y tierra) se convierten en el núcleo de un horno de "black fellows"2. Este proceso, que se repite continuamente durante muchos años, quizás siglos, da como resultado montículos que en realidad son hornos de los aborígenes, aunque a menudo se denominan incorrectamente túmulos (BEVERIDGE, 1869, p. 187).

En el párrafo transcripto se detalla para qué, cuándo y cómo se confecciona los oven mounds, y quienes intervienen en el proceso. El objetivo inmediato es procesar alimentos, una tarea familiar o multifamiliar, llevada adelante por mujeres. La confección y uso de los hornos requiere instrumentos simples, palo cavador y pinzas de madera, no obstante, con el transcurso del tiempo ello desemboca en grandes acumulaciones de sedimento.

James Dawson, nuestra segunda fuente, aporta una descripción similar:

Los hornos se hacen fuera de las viviendas cavando pozos en el suelo, enluciéndolos con barro y manteniendo el fuego hasta que estén bastante calientes, luego se retiran las brasas y se cubren los hoyos con pasto húmedo. La carne, el pescado o las raíces se ponen en cestas, que se colocan en el horno y se cubren con más pasto húmedo, grava, piedras calientes y tierra, y se mantienen tapadas hasta que estén cocidos. Esto se hace por la noche. Cuando la cocina es comunitaria - que suele ser el caso cuando conviven muchas familias - cada familia viene a la mañana siguiente y saca su cesto de alimentos para el desayuno (1881, en FRANKEL; MAJOR, 2017, p. 66).

También es similar y coherente la descripción de Curr (1883, en FRANKEL; MAJOR, 2017, p. 70):

La forma en que se usaban estos hornos era la siguiente: cuando había comida para hornear, las mujeres, con sus manos y palo cavador hacían un agujero en el montículo; si al hacerlo se encontraban con trozos de arcilla (porque no había piedra en esas partes), cubrían toscamente el 
fondo del agujero con ellos. Si no encontraban ninguno, rápidamente sacaban una cantidad para ese propósito con sus palos cavadores de algún lugar cercano. Estos terrones tenían aproximadamente el tamaño del puño de un hombre. Cubriendo el fondo del pozo con ellos, se encendió un fuego encima de estos, y sobre el fuego se arrojaron más terrones. Cuando el fuego se apaga, estos últimos se retiran a un lado y las brasas calientes al otro. Habiéndose limpiado así el agujero de todo, excepto de los de terrones calientes, estos últimos se esparcían finamente con hierba o con las hojas verdes de una hierba llamada pennyroyal, si era posible bien humedecida con agua. Por encima se depositaban, cuidadosamente empaquetados, los animales o las raíces a cocinar; luego otra capa de hierba húmeda y los trozos restantes de tierra caliente, por último ramas ardientes. Estos a menudo estaban cubiertos con una hoja de corteza y por encima tierra. En una o dos horas la comida estaba bien cocida y limpia.

En la segunda parte de la descripción de Beveridge (1869, p. 188) se ahonda en el uso que se les da en algunos parajes y circunstancias, a los oven mounds, pasando a ser lugares de residencia temporal. Señala cómo esto también contribuye a su elevación y asimismo cómo en un ciclo de ocupación-abandono coadyuvan los factores naturales en su formación.

Como regla general, los aborígenes no usan sus montículos de cocina para construir sus campamentos; sin embargo, existe una excepción a esto en las grandes llanuras de juncos inundadas del Bajo Murray, donde los hornos de los aborígenes son más numerosos y más grandes que cualquiera que haya visto en cualquier otra parte de Australia. Allí, donde las aguas (snow-waters) cubren las llanuras por millas a cada lado del río, los hornos sobresalen de la inundación, islotes perfectos de aspecto verde y refrescante a la vista, debido al gran crecimiento de la suculenta "saltbush"[...]. En estos montículos-islas los nativos, durante la época de las inundaciones, hacen sus campamentos, transportan su leña en canoas, a menudo a una distancia de cuatro o cinco millas. A veces, permanecen hasta un mes en una de estas pequeñas islas, viviendo del enorme y aceitoso bacalao del Murray, complementado con huevos de casi todas las clases de aves acuáticas y de las aves mismas. Por otro lado tienen el joven y suculento kumpung (bandera de hoja ancha), que brota a través del agua [...]. Por lo tanto, todos los artículos de consumo, incluso el material para la construcción de sus campamentos, deben ser llevados al lugar y, por supuesto, la basura diaria suma materialmente al crecimiento del montículo. Mientras la caza y la pesca continúen abundando, los nativos nunca piensan en cambiar sus campamentos, es decir, hasta que el lugar se vuelve demasiado ofensivo incluso para los olfativos aborígenes, entonces, se trasladan a otro montículo y dejan a cargo de los agentes naturales purificar el lugar abandonado. Cuando haya recuperado su aspecto prístino nuevamente será visitado (BEVERIDGE, 1869, p. 188).

Por último, en la tercera parte de la descripción, Beveridge (1869, p.188) aborda los enterramientos que se hallan en los montículos, lo que para el autor fue la causa que llevó a que se les atribuyera el carácter de túmulos.

En los hornos se encuentran con frecuencia esqueletos de nativos aborígenes; de ahí la idea predominante de que [los oven mounds] son túmulos; pero este hecho se explica fácilmente. Suponiendo que una vieja Lubra muere cuando resulta que solo hay una pequeña parte de la tribu a la que pertenece; se adopta el método más fácil de cubrir el cuerpo fuera de la vista y este es hacer raspando con sus palos cavadores un agujero en el suelo suelto y friable de un horno [...] se tapa y se olvida el cuerpo en muy poco tiempo. Los nativos no poseen ningún otro implemento para escarbar que no sean palos cavadores, por lo tanto, la tierra suelta es una gran consideración para ellos cuando tienen una tumba que cavar (BEVERIDGE, 1869, p. 188).

\section{Analogía, analogía relacional y prospectiva}

Claramente no existe un linaje evolutivo inmediato entre los montículos australianos y aquellos ubicados en la CLM, por lo que es indudable que no puede aplicarse una analogía histórica directa. Por lo tanto, plantear similitudes en los procesos de generación de los mismos requiere admitir un proceso de desarrollo convergente, entre grupos cazadores-recolectores-pescadores que 
vivieron en ambientes similares. Lo expuesto cumple los requerimientos de Clark (1953) para sustentar una analogía discontinua. Pero si consideramos los criterios de evaluación de analogía formales postulados por Wylie (1985, p. 97), la validez de la inferencia analógica se robustece y es mayor ya que estaríamos frente a una analogía relacional, en tanto que varias de las propiedades de la fuente no serían independientes, indicando una estructuración originada por un mismo "principio de conexión causal o cuasi causal” (WYLIE, 1985, p. 101). El principio relacional estaría dado por la adopción de un sistema de asentamiento-subsistencia similar, que se centra en recursos que al ser cocidos aumentan la biodisponibilidad de sus nutrientes. Los lugares de procesamiento y consumo se ubicaron en o próximos a donde se concentraban estos recursos vegetales. El uso de los HP en los montículos australianos a lo largo de siglos o milenios causó la acumulación o amontonamiento de los desechos que producen, principalmente material sedimentario termoalterado, que son evidencias de la acción del fuego, termóforos sedimentarios, restos de alimentación y artefactos descartados, tal como se observan en los montículos de la CLM (ver Tabla 1). Las observaciones históricas acerca del empleo de estos montículos para cocinar se ven contrastadas por las múltiples evidencias de la acción de fuego y estructuras de combustión. Pero no todos fueron sólo "lugares para cocinar", en algunas zonas y circunstancias, como ser en planicies extensas y durante el período de inundación, los oven mounds pasaron a ser lugares de residencia por períodos relativamente prolongados, ocasionando que los detritos generados diariamente también contribuyeran al proceso de elevación, lo cual es contrastado por la existencia de artefactos domésticos. Asimismo, procesos naturales concurrieron en su elevación y modelación.

Según las fuentes referidas, la construcción de esta particular arquitectura en tierra no requirió el empleo de herramientas elaboradas, sólo la repetición del uso de HT por dilatados períodos. Cómo herramientas se utilizaron palos cavadores y pinzas de madera, las cuales han de tener una limitada duración en el registro arqueológico. Tanto Beveridge (1869) como Curr (1883, en FRANKEL; MAJOR, 2017, p. 70) nos dan indicios de las características (terrones tenaces), forma de obtenerlo (con palo cavador) y procedencia (desde cualquier lugar cercano) del material sedimentario usado como termóforos y que devino en material constructivo. La dimensión social involucrada en este proceso de formación también se reseña, el procesamiento de los alimentos era realizado por mujeres de uno o más grupos familiares reunidos, donde eventualmente podían cocinar en forma individual utilizado un mismo horno comunitario.

Como se expone en la Tabla 1 hay un conjunto no menor de propiedades que se dan en la fuente y que estarían presentes en el sujeto, sustentando la base de la inferencia analógica. Además, numerosas observaciones etnográficas disponibles para la fuente también brindan una serie de informaciones sustancialmente importantes para el desarrollo de una agenda de investigación en el sujeto. Entre ellas destacamos las diferentes funcionalidades y tipos de ocupación de los montículos según su emplazamiento y la época del año en el que fueron ocupados, la distribución por género de las tareas, la composición y conexión de los miembros de los grupos funcionales vinculados a la recolección y procesamiento, y sus relaciones sociales. Por su parte las referencias sobre las prácticas mortuorias ${ }^{3}$ nos merecen una atención especial en tanto nos proporcionan singulares horizontes interpretativos $y / o$ insumos para formular hipótesis en un aspecto que en lo inmediato está muy alejado de lo económico. Beveridge (1869, p. 188) señala que luego de la inhumación "se olvida el cuerpo en muy poco tiempo" lo que no sólo da espacio para que no hubiere conflicto entre lo espiritual y lo cotidiano (seguir usando el espacio como campamento o cocina) sino que al mismo tiempo indicaría que no necesariamente hay una resignificación del lugar ocasionada por una inhumación. Por otra parte nos informa cómo la categoría de actor social ("mujer vieja”) y circunstancias de la muerte ("cuando sólo hay una pequeña sección de la tribu”) inciden en cómo y dónde se entierra: "raspando un agujero con sus 'palitos de cavar' en el suelo suelto y friable de un horno". Esto también presenta un correlato arqueológico en los montículos de la CLM, donde las fosas mortuorias fueron halladas a muy poca profundidad (Figura 3), y para aquellas 
inhumaciones más profundas, las diferencias entre las edades absolutas de los restos humanos y las capas arqueológicas también indican que se realizaron en fosas poco profundas, cuando los montículos tenían alturas más bajas. Por otro lado, la diversidad en las modalidades de inhumación (PINTOS; BRACCO, 1999; FEMENÍAS et al., 1991) y la composición sexo-etaria - sobre representación de individuos masculinos y adultos (FIGUEIRO, 2014) - que se observan en los montículos de la CLM puede tener un origen en conductas circunstanciales y oportunistas antes que en estrategias mortuorias planificadas, similar a lo descripto para los montículos australianos.

\section{Consideraciones finales}

En Uruguay la gran mayoría de las fuentes etnohistóricas disponibles refieren a grupos que devinieron en sociedades ecuestres, y por lo tanto, el uso de las analogías histórico-directas no es mayormente fiable para aproximarnos a tiempos prehistóricos. Para el caso de los montículos se suma que ellos no son mencionados en ninguna de las fuentes conocidas. Para su interpretación se ha apelado a analogías discontinuas por tres vías: 1 ) recurriendo a las fuentes etnohistorias tardías que proporcionan información de realidades culturales que distan mucho de aquellas que se desarrollaron en los tiempos previos a la introducción del ganado (ver BECKER, 1984, LÓPEZ; BRACCO, 2010); 2) a través de las analogías generales; y 3 ) por medio de otras interpretaciones arqueológicas.

El uso de la analogía en arqueología es esencialmente un método comparativo que al integra datos relacionales, constituyendo una poderosa herramienta destinada a generar hipótesis robustas, expandiendo las consecuencias observacionales a un mayor número de ítems adecuados para la contrastación. Desde este encuadre, y a partir de una serie de propiedades que comparten los montículos de la CLM con los oven mounds de Australia, hemos incrementado la fortaleza de la analogía utilizada como fuente de hipótesis para la interpretación de los montículos del sur de la CLM, objetivo de este trabajo. Las evidencias contrastadoras y las propiedades del registro arqueológico que surgen de este proceso ya fueron analizadas en otro lugar (vr.gr. BRACCO $e t$ al., 2020), las cuales son concurrentes con el modelo planteado, el cual sugiere el uso de los HP a lo largo de siglos o milenios como causa del amontonamiento -montículos sensu Ingold (2013)de los desechos que producen: sedimentos termoalterados, termóforos sedimentarios, restos de alimentación y artefactos. Dadas las similitudes contextuales observadas tanto en la generación de hipótesis dentro de la analogía relacional, como así también de las evidencias contrastadoras, la génesis propuesta para los montículos de CLM es el modelo más probable para su explicación. En lo inmediato, a nuestro juicio, es necesario disponer de miradas alternativas respecto a los procesos de elevación de estas estructuras. A mediano y largo plazo, las evidencias contrastadoras que se acumulen para cada modelo propuesto serán aquellas que permitan explicar con mayor o menor precisión su génesis.

\section{Notas}

1 Mujer nativa australiana

2 Denominación usada por los colonizadores para referirse a los hombres nativos australianos.

3 Cabe señalar también que la presencia de enterramientos tanto en los montículos de Australia como de la CLM produjo una "meta-analogía” al adjudicárseles en ambos casos, el carácter de túmulos ( ARECHAVALETA, 1892).

\section{Referencias}

AMEGHINO, Florentino. La Antigüedad del Hombre en el Plata. 2 Vols. Editorial La Cultura Argentina, Buenos Aires, 1880 [1947].

ARECHAVALETA, José. Viaje a San Luis. In: FIGUEIRA, J. H (Ed.) El Uruguay en la Exposición Histórica Americana de Madrid. Memoria. Montevideo: Dornaleche y Reyes, 1892. p. $65-91$

BAEZA, Jorge; PANARIO, Daniel. La horticultura indígena en las estructuras monticulares. Actas de las Primeras Jornadas sobre Cenozoico en 
Uruguay (20-21 de diciembre de 1999). Montevideo: SUG, INGEPA e UNCIEP, Facultad de Ciencias, 1999, p. 1-2.

BARRIOS PINTOS, Aníbal. $\mathbf{4 0 0}$ años de historia de la ganadería en Uruguay. Montevideo: Cruz del Sur, 2011.

BECKER, Ítala B. El indio y la colonización. Pesquisas - Antropología, n. 37, p. 1-286, 1984.

BEVERIDGE, Peter. Aboriginal Ovens. Journal of the Anthropological Society of London 7: clxxxvii-clxxxix. Published by: Royal Anthropological Institute of Great Britain and Ireland Stable, 1869.

BINFORD, Lewis. Methodological considerations of the archaeological use of ethnographic data. In: LEE, Richard B.; DEVORE, Irven (Eds.). Man the Hunter. Chicago: Aldine Publishing, 1968, pág. 268-273.

BINFORD, Lewis. Smudge pits and hide smoking: The use of analogy in archaeological reasoning. Am. Antiquity, n. 32, p. 1-12, 1967.

BINFORD, Lewis. Nunamiut Ethnoarchaeology. New York: Academic Press, 1978.

BINFORD, Lewis. Working at Archaeology. New York: Academic Press, 1983.

BRACCO, Diego. Guenoas. Uruguay: Ministério de Educación y Cultura. IMPO, 1998.

BRACCO, Diego. Los errores charrúa y guenoa-minuán. Jahrbuch für Geschichte Lateinamerikas, v. 41, p. 117-136, 2004.
BRACCO, Diego. Chanáes: aculturación y continuidad. Comechingonia. Revista De Arqueología, v. 21, n. 2, p. 305-331, 2017.

BRACCO, Roberto. Montículos de la Cuenca de la Laguna Merín: tiempo, espacio y sociedad. Latin American Antiquity, n. 17, p. 511-540, 2006.

BRACCO, Roberto. Lo crudo y lo cocido. Revista uruguaya de antropología y etnografía, v. 4, n. 2, p. 39-55, 2019.

BRACCO, Roberto, URES, Cristina. Ritmos y dinámica constructiva de las estructuras monticulares. Sector sur de la cuenca de la laguna Merín. Uruguay. In: LÓPEZ, José M.; SANZ, Maria. (Eds.) Arqueología y Bioantropología de las Tierras Bajas. Montevideo, Uruguay: Fhuce, Universidad de la República, 1999. p. 13-33.

BRACCO, Roberto; CABRERA, Leonel; LÓPEZ, José. La prehistoria de las tierras bajas de la cuenca de la laguna Merín. In: DURÁN, Alicia; BRACCO, Roberto (Eds.). Arqueología de las Tierras Bajas. Montevideo, Uruguay: Ministerio de Educación y Cultura, Comisión Nacional de Arqueología, 2000. p. 13-38.

BRACCO, Roberto; DEL PUERTO, Laura; INDA, Hugo; CASTIÑEIRA, Carola. Mid-Late Holocene Cultural and Environmental Dynamics in Eastern Uruguay. Quaternary International, n. 132, p. 37-45, 2005.

BRACCO, Roberto; INDA, Hugo; DEL PUERTO, Laura. Complejidad en montículos de la cuenca de la Laguna Merín y análisis de redes sociales. Intersecciones en Antropología, n, 16, n, 1, 271-286, 2015. 
BRACCO, Roberto; DEL PUERTO, Laura; INDA, Hugo; PANARIO, Daniel; CASTIÑEIRA, Carola; GARCÍA-RODRÍGUEZ, Felipe. The Relationship between Emergence of Mound Builders in SE Uruguay and Climate Change Inferred from Opal Phytolith Records. Quaternary International, n. 245, p. 62-73, 2011.

BRACCO, Roberto; PANARIO, Daniel; GUTIÉRREZ, Ofelia; DUARTE, Chistopher; BAZZINO, Andreina. Estructuras monticulares y hormigueros en el sur de la cuenca de la Laguna Merín: ¿Ingenieros ambientales y/o la estrategia del bricoleur? Revista de Antropología del Museo de Entre Ríos, v. 5, n. 1, p. 24-40, 2019a.

BRACCO, Roberto; PANARIO, Daniel; GUTIÉRREZ, Ofélia; BAZZINO, Andreina; DUARTE, Chistopher; ODINO, Rosario; REINA, Ethel. Mounds and Landscape in the Merín Lagoon Basin, Uruguay. In: INDA FERRERO, Hugo; GARCÍA RODRÍGUEZ, Felipe (Eds.). Advances in Coastal Geoarchaeology in Latin America. Suiza: Springer, Cham, 2019b, p. 103-129.

BRACCO, Roberto; DUARTE, Chistopher; GUTIÉRREZ, Ofelia; TASSANO, Marcos; NORBIS, Walter; PANARIO, Daniel. El fuego en los procesos constructivos de los montículos del sur de la cuenca de la Laguna Merín. Un aporte de la datación por luminiscencia (OSL-TL). Latin American Antiquity, p. 498-516, 2020a.

BRACCO, Roberto; DUARTE, Christopher; GUTIÉRREZ, Ofélia; PANARIO, Daniel. El fuego, los hornos de tierra y la elevación de los montículos de la cuenca de la Laguna Merín. Revista de Arqueología (en prensa), 2020b. BROCKWELL, Sally. Earth mounds In Northern Australia: A review. Australian Archaeology, v. 63, n. 1, p. 47-56, 2006.
CABRERA, Leonel; MAROZZI, Oscar. Las áreas domésticas de los "constructores de cerritos": el sitio CG14E01". In: Arqueología uruguaya hacia el fin del milenio. Montevideo, 2001. p. 55-68.

CAMERON, David W. The archaeology of Upper Palaeolithic art: aspects of uniformitarianism. Rock Art Research, n. 10, p. 3-17, 1993.

CAMPANELLI, Maurizio; MUIR, Jane; MORA, Alice; CLARKE, Daniel; GRIFFIN, Darren. Re-Creating an aboriginalearth oven with clayey heating elements: experimental archaeology and paleodietary implications. EXARC Journal, n. 2, 2018.

CASTIÑEIRA, Carola; BLASI, Adriana; BONOMO, Mariano; POLITIS, Gustavo; APOLINAIRE, Eduardo. Modificación Antrópica Del Paisaje Durante El Holoceno Tardío: Las Construcciones Monticulares En El Delta Superior Del Río Paraná. Revista de la Asociación Geológica Argentina, v. 71, n. 1, p. 33-47, 2014.

CLARK, John G. D. Archaeological theories and interpretations: Old World. In: KROEBER, Alfred (Ed.). Anthropology Today. Chicago: Univ. Chicago Press, 1953, p. 343-60.

COPÉ, Silvia M. A ocupação pré-Colonial do sul e sudeste do Rio Grande do Sul. In: KERN, Arno (Ed.). Arqueologia pré-histórica do Rio Grande do Sul. Porto Alegre: Mercado Aberto, 1991. p. 191-211.

DEL PUERTO, Laura. Interrelaciones humano-ambientales durante el Holoceno tardío en el este del Uruguay: Cambio climático y dinámica cultural. Tesis doctoral inédita, Programa de Desarrollo de las Ciencias Básicas, Universidad de la República, Montevideo, 2015. 
DEL PUERTO, Laura; BRACCO, Roberto; INDA, Hugo; GUTIÉRREZ, Ofelia; PANARIO, Daniel; GARCÍA-RODRÍGUEZ, Felipe. Assessing Links between Late Holocene Climate Change and Paleolimnological Development of Peña Lagoon using Opal Phytoliths, Physical, and Geochemical Proxies. Quaternary International, n. 287, p. 89-100, 2013.

DUARTE Chistopher; BRACCO, Roberto. Procesos de elevación de los montículos del este de Uruguay y sur de Brasil. Modelo de crecimiento y dataciones luminiscentes. Anuario de Arqueología, 2021 (En prensa).

DUARTE, Christopher; BRACCO, Roberto; PANARIO, Daniel; TASSANO, Marcos; CABRERA, Mirel; BAZZINO, Andreina; DEL PUERTO, Laura. Datación de estructuras monticulares por OSL/TL. Revista de Antropología del Museo de Entre Ríos, n. 3, p. 14-26, 2017.

FEMENÍAS, Jorge; LÓPEZ, José; MARTÍNEZ, Eliane; FUSCO, Nelsy; CABRERA, Leonel; CURBELO, Carmen; BRACCO, Roberto. Tipos de enterramiento en estructuras monticulares en la cuenca de la laguna Merín. Revista do CEPA, n. 19, p. 139-155, 1991.

FERRATER MORA, José. De la materia a la razón. Madrid: Alianza Editorial, 1979.

FIGUEIRO, Gustavo. Bioarqueología en el Uruguay: situación actual y perspectivas futuras. In: LUNA, Leandro; ARANDA, Claudia; SUBY, Jorge (Eds.). Avances recientes en la bioarqueología latinoamericana. Buenos Aires: Grupo de Investigación en Bioarqueología, 2014. p. 47-68.

FRANKEL, David; MAJOR, Janine. Victorian Aboriginal Life and Customs through Early
European Eyes. La Trobe University EBureau, Melbourne, 2017.

GÁNDARA, Manuel. La Analogía Etnográfica como Heurística: Lógica Muestreal, Dominios Ontológicos e Historicidad. In: SUGIURA, Yoko; SERRA, Mari C. (Eds.) Etnoarqueología. Coloquio Bosch-Gimpera. Instituto de Investigaciones Antropológicas. Universidad Nacional Autónoma de México. México, 1990. p. 43-82.

GÁNDARA, Manuel. La inferencia por analogía: más allá de la analogía etnográfica. In: Etnoarqueología de la Prehistoria, Barcelona, 2006. p. 13-23.

GIANOTTI, Camila. Paisajes sociales, monumentalidad y territorio en las tierras bajas de Uruguay. Tesis doctoral inédita, Departamento de Historia I, Universidad de Santiago de Compostela, España, 2015.

GIANOTTI, Camila; DEL PUERTO, Laura; INDA, Hugo; CAPDEPONT, Irina. Construir para producir: Pequeñas elevaciones en tierra para el cultivo del maíz en el sitio Cañada de los Caponcitos, Tacuarembó (Uruguay). Cuadernos del Instituto Nacional de Antropología y Pensamiento Latinoamericano, v. 1, n. 1, p. 12-25, 2013.

GODOY, Luis A. Sobre la estructura de las analogías en ciencias. INCI [online]. v. 27, n. 8 , p. 422-429, 2002.

HALL, Brian K. Descent with Modification: The Unity Underlying Homology and Homoplasy as Seen Through an Analysis of Development and Evolution. Biological Review, n. 78, p. 409-43, 2003. 
HODDER, Ian. Interpretación en Arqueología. Corrientes actuales. Barcelona, Crítica, 1988.

INGOLD, Tim. Making: Anthropology, Archaeology, Art and Architecture. Oxon: Routledge, 2013.

IRIARTE, José. Mid-Holocene Emergent Complexity and Landscape ransformation: The Social Construction of Early Formative Communities in Uruguay, La Plata Basin. Tesis doctoral inédita, Department of Anthropology, University of Kentucky, Lexington, 2003.

IRIARTE, José; HOLST, Irene; MAROZZI, Oscar; LISTOPAD, Claudia; ALONSO, Enrique; RINDERKNECHT, Andrés; MONTAÑA, Juan. Evidence for Cultivar Adoption and Emerging Complexity during the Mid-Holocene in the La Plata Basin. Nature, n. 432, p. 614-617, 2004.

JONES, Robert; MORRISON, Michael; ROBERTS, Amy. River Murray and Mallee Aboriginal Corporation. An Analysis of Indigenous Earth Mounds on the Calperum Floodplain, Riverland, South Australia. Journal of the Anthropological Society of South Australia, n. 41, p. 18-61, 2017.

LANE, Paul, J. Hunter-gatherer-fishers, ethnoarchaeology and analogical reasoning. In: CUMMINGS, Vicki; JORDAN, Peter; ZVELEBIL, Marek (Eds.). Oxford Handbook of the Archaeology and Anthropology of Hunter-Gatherers. Oxford: Oxford University Press. 2014. p. 104-50.

LYMAN, R. Lee, O’BRIEN, Michael J. 'The Direct Historical Approach and Analogical Reasoning in Archaeology'. Journal of Archaeological Method and Theory, v. 8, 2001, p. 303-342.
LÓPEZ, José M. Las estructuras tumulares (cerritos) del litoral atlántico uruguayo. Latin American Antiquity, n. 12, p. 231-255, 2001.

LÓPEZ, José M.; BRACCO, Diego. Minuanos. Apuntes y notas para la historia y la arqueología del territorio Guenoa-Minuan (Indígenas de Uruguay, Argentina y Brasil). Montevideo: Linardi y Risso, 2010.

LOPONTE, Daniel; ACOSTA, Alejandro; TCHILINGUIRIÁN, Paulo. Estructuras "Monticulares", Unidades Arqueológicas y Falsas Premisas. Anuário de Arqueologia, n. 8, 2016, p. 45-78.

LOUREIRO, André G. Sítio PT-02-Sotéia: análise dos processos formativos de um Cerrito na região Sudoeste da Laguna dos Patos/RS. Dissertação (Mestrado em Arqueologia) - Museu de Arqueologia e Etnologia, Universidade de São Paulo, São Paulo, 2008.

MARTIN, Sarah. Palaeoecological evidence associated with earth mounds of the Murray Riverine Plain, south-eastern Australia. Environmental Archaeology, n. 16, p. 162-172, 2011.

MILHEIRA, Rafael G.; GIANOTTI, Camila. The Earthen Mounds (Cerritos) of Southern Brazil and Uruguay. In: SMITH, Claire (Ed.). Encyclopedia of Global Archaeology. Suiza: Springer, Cham, 2018. p. 1-9.

MORGADO, Antonio, BAENA, Javier. Experimentación, Arqueología experimental y experiencia del pasado en la Arqueología actual. In: MORGADO, Antonio; BAENA PREYSLER, Javier; GARCÍA GONZÁLEZ, David (Eds.). La Investigación Experimental aplicada a la Arqueología. Málaga: Ronda, 2011. p. 21-28. 
MORENO, Federica. La gestión de los recursos animales en la prehistoria del este de Uruguay (4000 años aP-siglo XVI). Tesis doctoral inédita, Universitat Autònoma de Barcelona: Departament d'Antropologia Social i Cultural, 2014.

MUT, Patricia. Paleodieta de los pobladores prehistóricos del este del Uruguay: Un retrato isotópico. Anuario de Arqueología 2015, p. 147-178, 2015.

PEREGRINE, Peter. N. Cross-Cultural Comparative Approaches in Archaeology. Annual Review of Anthropology, v. 30, n. 1, p. 1-18, 2001.

PINTOS, Sebastian; BRACCO, Roberto. Modalidades de Enterramiento y Huellas de Origen antrópico en especímenes Óseos Humanos. In: LÓPEZ, José M.; SANS, Monica (Eds.). Arqueologia y Bioantropologia de las Tierras Bajas, p. 81-106, 1999.

PINTOS, Sebastian; CAPDEPONT, Irina. Arqueología en la Cuenca de la Laguna de Castillos. Apuntes sobre complejidad cultural en sociedades cazadoras-recolectoras del Este del Uruguay. ArqueoWeb - Revista sobre Arqueología en Internet, n. 3, p. 1-15, 2001.

PRÜMERS, Heiko. Los montículos artificiales de la Amazonía. In: ROSTAIN, Sthépen; BETANCOURT, Carla Jaimes (Eds.). Las Siete Maravillas de la Amazonía precolombina. Bonner Amerikanistische Studien Bonn Americanist Studies / Estudios Americanistas de Bonn, n. 53, 2017. p. 47-71.

SCHMITZ. P. Ignácio; H. ROGGE, Jairo. 8.400 anos de ocupação indígena nas margens do rio Paraguai. In: CHAMORRO, Graciela; COMBÈS, Isabelle (Orgs.). Povos Indígenas em Mato Grosso
Do Sul: história, cultura e transformaçóes sociais. Dourados, MS: Ed. UFGD, 2015. p. 39-50.

SCHMITZ, Pedro Ignácio. Sítios de Pesca Lacustre em Rio Grande, RS, Brasil. Tesis (obtención del grado de Livre-docente) Universidade Católica do Rio Grande do Sul, Instituto Anchietano de Pesquisas, Universidade do Vale de Rio dos Sinos, São Leopoldo, 1976.

SEAWRIGTH, Caroline. Analogy and ethnography: a straitjacket for archaeological explanation?. ARC4ICA. La Trobe University, 2015.

STUART MILL, John. A System of Logic, Rationative and Inductive, Being a Connected View of the Principles of Evidence, and the Methods of Scientific Investigation. London, 1843.

SUÁREZ, Diego. Arqueología experimental y paleoetnobotánica de los constructores de cerritos del este del Uruguay: Una aproximación a partir del registro macrobotánico del sitio CH2D01. Tesis de maestría inédita, Facultad de Humanidades y Ciencias de la Educación, Universidad de la República, Montevideo, 2018.

TOULMIN, Stephen. The Uses of Argument. Cambridge: Cambridge University Press, 1958.

TRILLAS, Enric. La Inteligencia Artificial. Madrid: Editorial Debate, 1998.

VERDESIO, Gustavo. La invención del Uruguay : la entrada del territorio y sus habitantes a la cultura occidental. Montevideo, Uruguay: Editorial Graffiti: Editorial Trazas, 1996.

VILA, Assumpció, ESTEVEZ, Jordi. Calibrando el método: Arqueologia en Tierra del Fuego. 
Archeologia postmedievale, n. 4, p. 199-207, 2000.

WESTELL, Craig; WOOD, Vivienne. An Introduction to Earthen Mound Sites in South Australia. Journal of the Anthropological Society of South Australia, n. 38, p.30-65, 2014.

WILLEY, Gordon R. Archaeological theories and interpretation: New World. In: KROEBER, Alfred L. (Ed.). Anthropology Today, Chicago: University of Chicago Press, 1953. p. 361-385.

WYLIE, Alison. The Reaction against Analogy. Advances in Archaeological Method and Theory, n. 8, p. 63-111, 1985. 


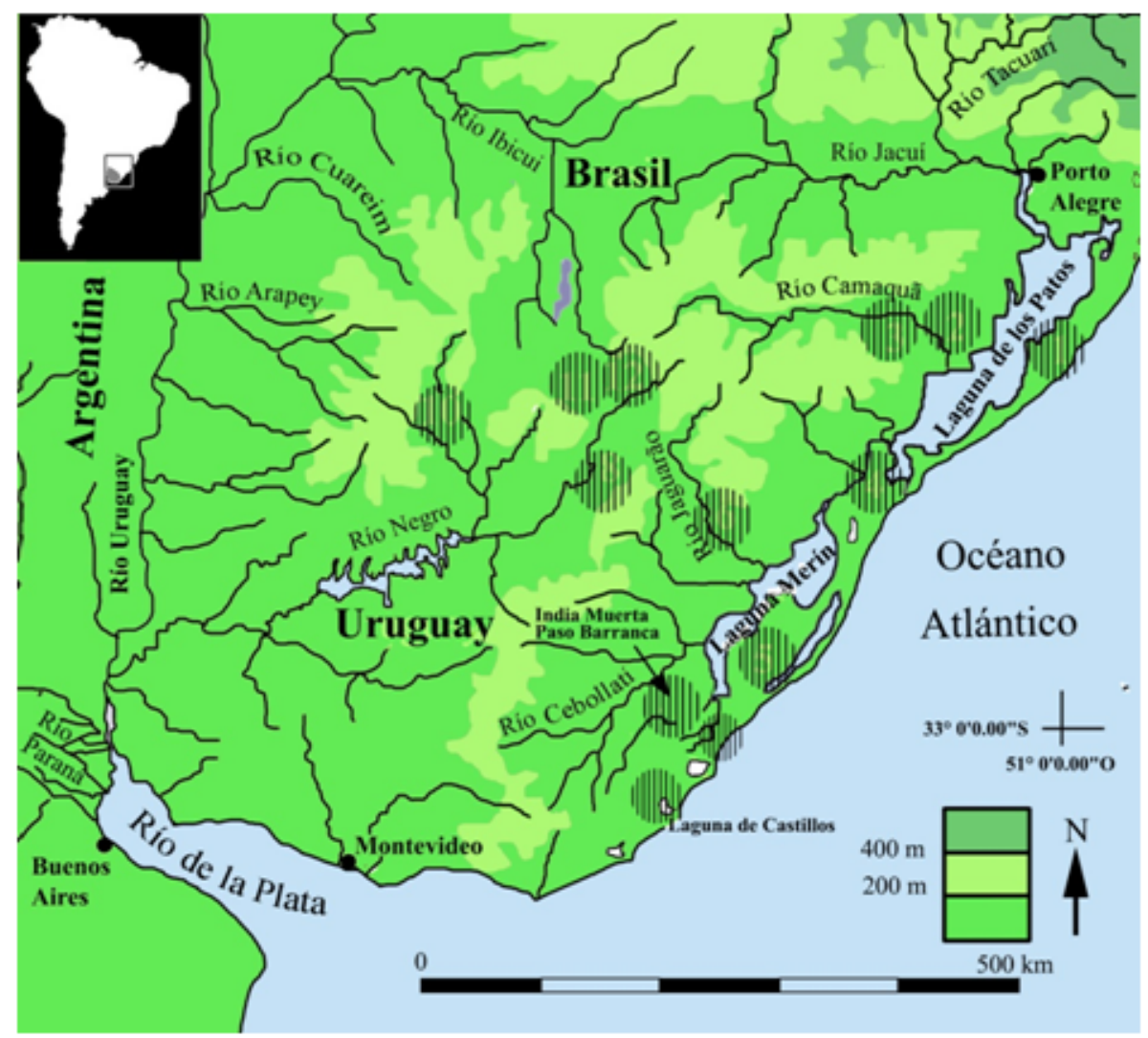

Figura 1 - Mapa de distribución de sitios con montículos en latitudes medias de la vertiente atlántica sudamericana.

Fuente: Basado en Bracco y colaboradores (2015); López y colaboradores (2017); Milheira y colaboradores (2016).

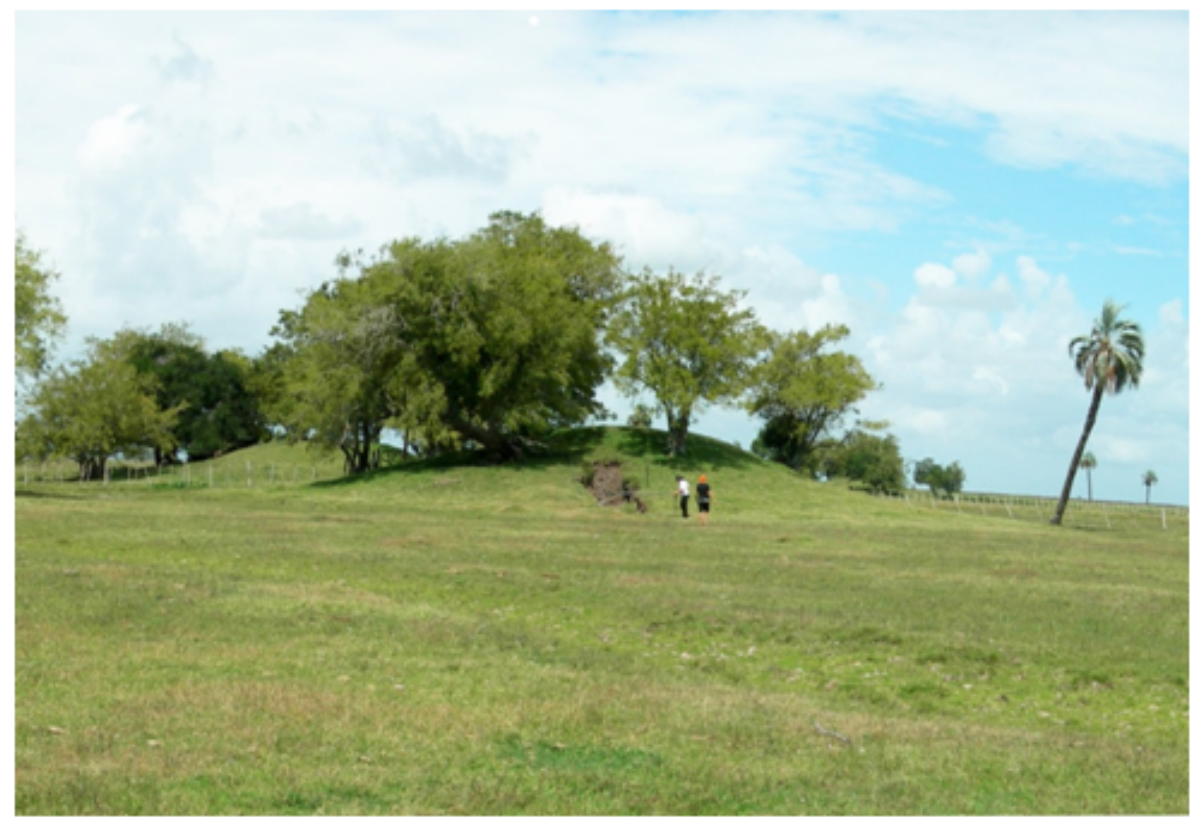

Figura 2 - Montículos del sitio PSL ubicado en márgen derecha del río San Luis, centro del departamento de Rocha, Uruguay.

Fuente: Acervo fotográfico de Roberto Bracco (2005). 


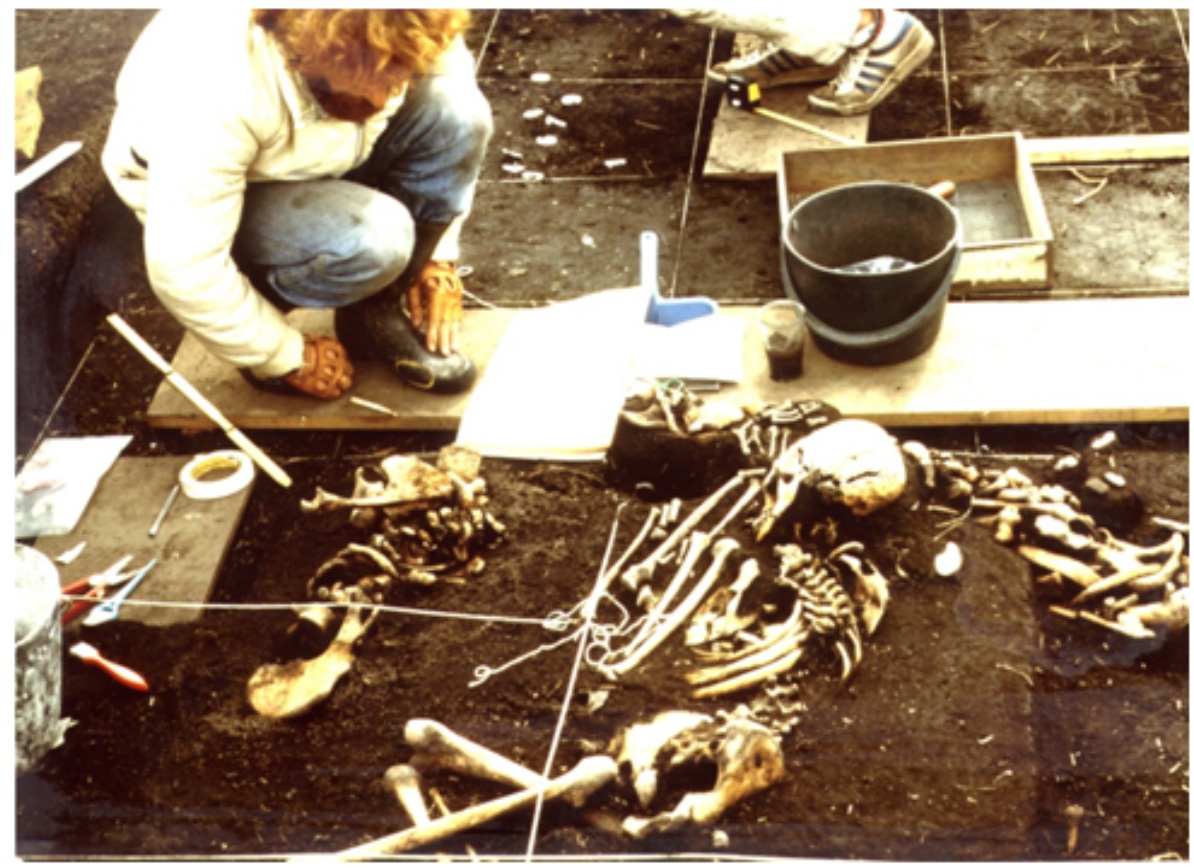

Figura 3 - Excavación A, sitio CH2D01, bañado de San Miguel, Rocha. Se observa un enterramiento primario y dos secundarios ("paquetes"). El punto más bajo de la planta de excavación no supera 105 Fuente: Acervo fotográfico de Roberto Bracco (1988). 